This is a revised personal version of the text of the final journal article, which is made available for scholarly purposes only, in accordance with the journal's author permissions. The full citation is:

Yirong, C., Zhang, W., Heaven, S. and Banks, C.J., 2017. Influence of ammonia in the anaerobic digestion of food waste. Journal of Environmental Chemical Engineering 5(5), 5131-5142. https://doi.org/10.1016/i.jece.2017.09.043

\title{
Influence of ammonia in the anaerobic digestion of food waste
}

\section{Author names and affiliations}

Chaowana Yirong ${ }^{\text {a, }}$, Wei Zhang ${ }^{\text {a }}$, Sonia Heaven ${ }^{\text {a }}$ and Charles J. Banks ${ }^{\text {a }}$

${ }^{a}$ Faculty of Engineering and the Environment, University of Southampton, Southampton, SO17 1BJ, UK

b Present address: Prince of Songkla University, Songkhla, Faculty of Science and Industrial Technology, Suratthani Campus, 31 Moo 6, Makham Tia, Muang Suratthani, Suratthani, Thailand 84000

\begin{abstract}
Ammonia toxicity was investigated in mesophilic $\left(37^{\circ} \mathrm{C}\right)$ and thermophilic $\left(55^{\circ} \mathrm{C}\right)$ digesters using high and low-nitrogen food wastes (FW). Mesophilic inoculum was successfully acclimated to thermophilic conditions by a step change in temperature followed by incremental increases in organic loading rate (OLR). Digestion performance and stability were monitored via volatile fatty acid (VFA) profiles, alkalinity, specific methane production (SMP) and volatile solids (VS) destruction. High-nitrogen mesophilic digesters stabilised by day 70 and responded well to increases in OLR, with a SMP of 0.45 $\mathrm{L} \mathrm{CH}_{4} \mathrm{~g}^{-1} \mathrm{VS}$, stable $\mathrm{pH}$, and VFA $<0.2 \mathrm{~g} \mathrm{~L}^{-1}$. Thermophilic digesters fed on high and low-nitrogen FWs showed almost identical responses to acclimatisation. Behaviour then deviated, with high-nitrogen digesters accumulating VFA. Stable $\mathrm{pH}$ could be maintained for up to 310 days before eventual failure at total ammonia nitrogen (TAN) concentration $>5.0 \mathrm{~g} \mathrm{~N} \mathrm{~L}^{-1}$, although accumulation of propionic and other longer-chain VFA began at TAN $\sim 3.5 \mathrm{~g} \mathrm{~N} \mathrm{~L}^{-1}$. The low-nitrogen digesters showed no VFA accumulation, and had a SMP of $\sim 0.39 \mathrm{~L} \mathrm{CH}_{4} \mathrm{~g} \mathrm{VS} \mathrm{L}^{-1}$ day $^{-1}$ with $91 \%$ VS destruction. After 384 days the TAN concentration was increased from $\sim 0.7 \mathrm{~g} \mathrm{~N} \mathrm{~L}^{-1}$ by urea addition. This resulted in progressive VFA accumulation in one digester when TAN reached $\sim 3.5 \mathrm{~g} \mathrm{~N} \mathrm{~L}^{-1}$, while stable operation at very low VFA was possible at up to $\sim 2.5 \mathrm{~g} \mathrm{~N} \mathrm{~L}^{-1}$ in the second digester. The results confirmed acclimatisation to thermophilic conditions was possible on a far shorter timescale than to high TAN concentrations.
\end{abstract}

Keywords Ammonia inhibition; thermophilic digestion; methane production; total ammonia nitrogen; acclimatisation

\section{$1 \quad$ Introduction}

Anaerobic digestion is an effective technology for recovering value from food wastes in the form of biogas as a renewable fuel and nutrients for recycling back to agriculture. These wastes arise at various points in the production and distribution chain: their characteristics and composition reflect this, and digestion of a number of relatively homogeneous wastes and effluents from food processing has been practiced for a long time [1]. Despite some regional 
differences, the composition of food waste from domestic properties and catering establishments is relatively similar in many parts of the world [2]; but it is only recently that source segregated collection of this material has become popular, meaning that larger volumes are available for processing. Pilot-scale studies carried out with this material in 2003 considered both mesophilic and thermophilic operation [3] and based on these studies the first full-scale commercial demonstration plant was designed as a continuously stirred tank reactor (CSTR) operated at mesophilic temperature [4]. Since then a number of alternative technologies for food waste digestion have been suggested including two phase systems [5] and leach bed reactors $[6,7]$. Digestion of source segregated domestic food waste is now a popular approach in many areas of the world $[8,9]$, with 400 plants in the UK alone contributing $480 \mathrm{MW}$ to the electricity grid in 2016 [10]. Operation of food waste digesters at thermophilic temperatures remains challenging, however, and is only possible through interventions to reduce inhibition such as dilution [11, 12] or ammonia removal [13], both of which require additional engineering and control systems. A detailed understanding of the threshold limits of inhibition is therefore important to establish the design and operating criteria for implementation of these interventions.

The problem of inhibition arises because most domestic food wastes have a relatively high content of proteinaceous material, which on hydrolysis may lead to elevated concentrations of total ammonia nitrogen (TAN). A proportion of this TAN, depending on temperature and $\mathrm{pH}$, is present as free ammonia nitrogen (FAN). Even under mesophilic conditions this can cause operational problems during digestion [14-16] and in thermophilic conditions it has led to severe inhibition, accumulation of volatile fatty acids (VFA), and eventual process failure $[13,17]$. A substantial amount of information is now available on threshold concentrations for TAN inhibition in mesophilic conditions [18-20], with reported values generally in the range of 3-5 $\mathrm{g} \mathrm{N} \mathrm{L}^{-1}$. The uncertainty in this value is due to several factors that may influence the onset of process instability or loss in digestion performance, such as the $\mathrm{pH}$, operating temperature and microorganism adaptation. With the development of new genetic and molecular tools, some new insights are now emerging into how communities might adapt or acclimatise to high ammonia environments [21, 22].

Under thermophilic conditions a greater proportion of TAN is present as the more inhibitory free ammonia as the equilibrium is temperature-dependent [23]; but less information is available on the toxic thresholds in thermophilic systems, and virtually none concerning food waste digestion. The problem is a circular one in that, firstly, there are few sources of thermophilic inoculum that has been 'acclimatised' to high-nitrogen feedstock; secondly, the process of acclimatisation to thermophilic temperatures can itself lead to signs of instability [24]. Hence, when a mesophilic inoculum is adapted to thermophilic conditions using a typical domestic food waste as the feedstock, fully stable operation may not have been established at the higher temperature before instability starts to occur due to the build-up of ammonia. This situation can lead to uncertainty regarding which stress factor leads to digester instability, as monitored by VFA accumulation, loss of biogas production and other key indicators. To ensure that these two factors could be clearly separated and therefore accurately reported, the current work had the following specific objectives: i) to run digesters on high nitrogen (high-N) food waste (FW) under mesophilic conditions in order to demonstrate that the material itself contained no inherently toxic or inhibitory components at the loading used, and establish a baseline level of digestion performance; ii) to acclimate inoculum from the same source to thermophilic conditions using a low-nitrogen (low-N) FW to demonstrate that the acclimatisation method was successful; iii) to feed an acclimated stable thermophilic inoculum on high-N FW from the same source to demonstrate the effect 
of the increased nitrogen content; and iv) to find the critical threshold for ammonia toxicity in the digesters fed on low-N FW by increasing the TAN, by adding urea both gradually and as a single dose. A further purpose of the final objective was thus to give an insight into the mechanism of adaptation to high TAN concentrations by differentiating between a gradual growth-mediated response and that to a shock load. In all cases the onset of instability was monitored by reference to VFA concentrations and profiles, and changes in alkalinity ratio, $\mathrm{pH}$ and biogas productivity and composition.

The current work is thus the first long-term comparative study of thermophilic and mesophilic digestion of source segregated domestic food waste in a parallel trial supported by compositional analysis and stability and performance data.

\section{$2 \quad$ Materials and methods}

\subsection{Food wastes}

The high-N FW was source segregated domestic waste collected commercially by Veolia Environmental Services (UK) Ltd from households in Eastleigh, Hampshire, UK. The waste is collected in biodegradable plastic bags, and a representative sample of these with a weight of around $300 \mathrm{~kg}$ was prepared for use throughout the experimental work. The FW was taken out of the bags, and any obvious non-food contamination removed along with any large bones and seeds. The sample was then ground (S52/010 Waste Disposer, IMC Limited, UK) to a homogeneous pulp, mixed thoroughly in a single batch and frozen at $-18{ }^{\circ} \mathrm{C}$ in snap-top plastic containers in $\sim 3 \mathrm{~kg}$ aliquots. When needed, the feedstock was thawed and stored at 4 ${ }^{\circ} \mathrm{C}$ and used within a period of a few days.

The low-N FW was made using mainly vegetables and fruits with a small amount of meat, dairy products and bread (see Supplementary materials for recipe). The ingredients were chopped, mixed and then ground before freezing as above. Before use the thawed material was mixed with cellulose powder ( $\alpha$-cellulose C8002, Sigma-Aldrich) to give a volatile solids (VS) concentration similar to that of the high-N FW.

\subsection{CSTR digesters}

Four pairs of 4-L working volume anaerobic digesters of a continuously-stirred tank reactor (CSTR) design were used. These were constructed of PVC tube with gas-tight top and bottom plates. The top plate was fitted with a gas outlet, a feed port sealed with a rubber bung, and a draught tube liquid seal through which an asymmetric bar stirrer was inserted with a $40 \mathrm{rpm}$ motor mounted directly on the plate. Digester temperature was maintained at $37 \pm 1{ }^{\circ} \mathrm{C}$ (mesophilic) or $55 \pm 1{ }^{\circ} \mathrm{C}$ (thermophilic) by circulating water from a thermostaticallycontrolled bath through heating coils around the digesters. Biogas was measured using tipping-bucket gas counters with continuous datalogging. Gas counter calibration was checked weekly by collecting the gas produced over a one-day period in a gas-impermeable bag and measuring its volume in a weight-type gasometer [25]. All gas volumes reported are corrected to standard temperature and pressure (STP) of $0{ }^{\circ} \mathrm{C}, 101.325 \mathrm{kPa}$.

\subsection{Digester set-up, operation and monitoring}

Eight digesters were inoculated with digestate taken from a mesophilic digester treating municipal wastewater biosolids (Millbrook wastewater treatment works, Southampton, UK). 
The digesters were fed semi-continuously by addition of substrate on a daily basis with removal of digestate to maintain a constant volume. During operation all digesters were supplemented with the 5-element TE stock solution (Table 1) at the rate of $1 \mathrm{~mL} \mathrm{~kg}^{-1}$ wet weight (WW) of feedstock added, unless otherwise noted.

Four of the digesters (T1-T4) were acclimated to thermophilic conditions by increasing the temperature to $55{ }^{\circ} \mathrm{C}$ in one step and then not feeding for 6 days. One pair of these (T1 and T2) was fed on low-N FW and the other pair (T3 and T4) on high-N FW. Feeding was started at an organic loading rate (OLR) of $0.5 \mathrm{~g} \mathrm{VS} \mathrm{L}^{-1}$ day $^{-1}$ and was increased daily by $0.05 \mathrm{~g} \mathrm{VS}$ $\mathrm{L}^{-1}$ day $^{-1}$ until $2 \mathrm{~g} \mathrm{VS} \mathrm{L}^{-1}$ day $^{-1}$ was reached on day 39. T1-T4 were then run at OLR $2 \mathrm{~g}$ VS $\mathrm{L}^{-1}$ day $^{-1}$ for the duration of the experiment, except when failure conditions were apparent, at which point feeding was stopped to allow recovery.

The other four digesters (M1-M4) were maintained at mesophilic temperature and fed on high-N FW at an OLR of $2 \mathrm{~g} \mathrm{VS} \mathrm{L}^{-1}$ day $^{-1}$ for a period of 97 days to ensure stable operation. The OLR on M3\&4 was then increased to $3 \mathrm{~g} \mathrm{VS} \mathrm{L}^{-1}$ day $^{-1}$ by raising the loading by $0.05 \mathrm{~g}$ VS L ${ }^{-1}$ day $^{-1}$ every two days over a 3 -week period. Starting on day 177 , the OLR was increased over a 5-week period to $3 \mathrm{~g} \mathrm{VS} \mathrm{L}^{-1} \mathrm{day}^{-1}$ in M1\&2 and to $4 \mathrm{~g} \mathrm{VS} \mathrm{L}^{-1}$ day $^{-1}$ in M3\&4. These OLRs were then maintained until the end of the experiment on day 296.

In the second part of the study the ammonia concentration in the thermophilic digesters receiving low-N FW (T1 and T2) was raised by adding urea. This was added to T1 on day 384 as a single dose of $20.0 \mathrm{~g}$ aimed at increasing the TAN concentration to $\sim 2.5 \mathrm{~g} \mathrm{~N} \mathrm{~L}^{-1}$. T1 was then left for 80 days without further urea addition to allow acclimatisation, after which the TAN content was raised gradually to $\sim 3.5 \mathrm{~g} \mathrm{~N} \mathrm{~L}^{-1}$ by adding urea in the daily feed to give this target concentration. The TAN concentration was further increased between day 750 and 875 to a final value of around $\sim 4.2 \mathrm{~g} \mathrm{~N} \mathrm{~L}^{-1}$. In T2 the TAN concentration was increased to $\sim 2.5 \mathrm{~g} \mathrm{~N} \mathrm{~L}^{-1}$, but this was done gradually by adding an initial dose of $7.7 \mathrm{~g}$ of urea to the $\mathrm{T} 2$ digester on day 441 and then adding urea to the daily feed. This allowed comparison with the effect of the shock urea load applied to T1. The TAN concentration in T2 was then raised to $\sim 3.0 \mathrm{~g} \mathrm{~N} \mathrm{~L}^{-1}$ between day 750-875 in order to provide a detailed profile of the stability parameters around the threshold ammonia toxicity threshold.

Digester operational modes during the experimental period are summarised in Table 2.

\subsection{Analytical methods}

Total and volatile solids (TS and VS) were measured according to Standard Method $2540 \mathrm{G}$ [26] using a Heraeus Function Line Series oven and a 201/301 Carbolite muffle furnace. pH was determined using a Jenway 3010 meter (Bibby Scientific Ltd, UK) with a combination glass electrode calibrated in buffers at $\mathrm{pH} \mathrm{4,} 7$ and 9.2 (Fisher Scientific, UK). Alkalinity was measured by titration with $0.25 \mathrm{~N} \mathrm{H}_{2} \mathrm{SO}_{4}$ to endpoints of $\mathrm{pH} 5.75$ and 4.3 using an automatic digital titration burette system (SCHOTT titroline easy), to allow calculation of total (TA), partial (PA) and intermediate alkalinity (IA) [27]. Total Kjeldahl Nitrogen (TKN) was determined after acid digestion, by steam distillation and titration. This used a BÜCHI Digestion Unit K-435 with $\mathrm{H}_{2} \mathrm{SO}_{4}$ and $\mathrm{K}_{2} \mathrm{SO}_{4}$ as the reactants and $\mathrm{CuSO}_{4}$ as the catalyst to convert amino-nitrogen and free ammonia $\left(\mathrm{NH}_{3}\right)$ to ammonium $\left(\mathrm{NH}_{4}{ }^{+}\right)$. This was then measured as total ammonia nitrogen (TAN) using a BÜCHI Distillation Unit K-350 with $\mathrm{NaOH}$ addition, followed by collection of the distillate in boric acid indicator and titration with $0.25 \mathrm{~N} \mathrm{H}_{2} \mathrm{SO}_{4}$. VFA concentrations were determined by gas chromatography (Shimadzu 
GC-2010), with a flame ionisation detector and a capillary column (SGE BP-21) and helium as carrier gas. Samples were acidified to $10 \%$ using formic acid and measured against mixed standards of 50, 250 and $500 \mathrm{mg} \mathrm{L}^{-1}$ of acetic, propionic, iso-butyric, n-butyric, iso-valeric, valeric, hexanoic and heptanoic acids. Biogas composition $\left(\mathrm{CH}_{4}\right.$ and $\left.\mathrm{CO}_{2}\right)$ was determined using a Varian star 3400 CX Gas Chromatograph fitted with a packed stainless steel SUPELCO 80/100 mesh porapack-Q column and a TCD detector. The GC was calibrated with a standard gas containing $65 \% \mathrm{CH}_{4}$ and $35 \% \mathrm{CO}_{2}$ (v/v) (BOC, UK).

Further characterisation was carried out on samples prepared by air drying to constant weight and then milled to a particle size $\leq 0.5 \mathrm{~mm}$ in a micro-hammer mill (Retsch, Germany). Calorific values (CV) were determined using a bomb calorimeter (CAL2k-ECO, South Africa). Carbohydrates were determined after preliminary acid hydrolyis using $72 \%$ sulphuric acid in an orbital shaker (1 hour at 150-200 rpm) [28]. The hydrolysate was autoclaved at $121^{\circ} \mathrm{C}$ for 1 hour and analysed using a Dionex HPLC with an EC-400 detector and fitted with a Carbopac PA1 column $(250 \times 4 \mathrm{~mm})$ in combination with a Carbopac guard column $(25 \times 4$ $\mathrm{mm}$ ) (Dionex Corp, Sunnyvale, USA). Lipids were measured after Soxhlet extraction using n-hexane [29]. Inorganic elements were extracted in nitric acid and the extract filtered and diluted to $50 \mathrm{~mL}$ with deionised water (Milli-Q Gradient, Millipore, Watford, UK).

Phosphorus was measured by the ammonium molybdate spectrometric method [30].

Digestate samples for trace element determination (Co, Fe, Ni, Mo, Se) were sent to an external laboratory for analysis by ICP-MS (LGC, Teddington, UK). Fibre analysis (hemicellulose, cellulose and lignin) for low-N FW was done using the Fibercap method [31] in a FOSS kit FibretecTM 2023 (Hillerød, Denmark). Characterisation of the FW for trace element and fibre content and elemental composition was carried out by MTT Agrifood Research, Finland. Biochemical methane potential (BMP) was determined as described in [16] with a test duration of 28 days.

\subsection{Calculation}

Ammonia toxicity thresholds are expressed as TAN concentrations at the temperature and $\mathrm{pH}$ as measured, and this data is then used to calculate the equivalent FAN concentrations [32]. Theoretical CV was calculated based on the elemental composition, using the Dulong equation according to the method in Combustion file 24 [33]; and on the biochemical composition according to the values for protein, lipid and carbohydrate suggested by Angelidaki and Sanders [34]. The maximum theoretical methane production (ThMP) and biogas methane content was calculated from the elemental composition using the Buswell equation in conjunction with Avogadro's law $[34,35]$. For calculation of energy recovery the calorific value (higher heat value) of methane was taken as $39.84 \mathrm{MJ} \mathrm{m}^{-3} \mathrm{CH}_{4}$ at STP. VS destruction was calculated using a mass balance approach based on digestate VS concentration and taking into account the reduction in digestate volume.

\section{$3 \quad$ Results and discussion}

\subsection{Feedstock and inoculum characteristics}

The characteristics of the two types of FW are shown in Table 3, and of the inoculum in Table 4. The low-N FW had a TKN content of $1.45 \%$ on a TS basis, reflecting its ingredients which were mainly fruit and vegetables. The TKN content of the high-N source segregated domestic food was $3.09 \% \mathrm{TS}$; in this and other respects it was typical of source segregated food wastes of this type [36]. The $\mathrm{C} / \mathrm{N}$ ratios of the low and high-N FWs based on elemental 
composition were 16.5 and 46.8 respectively. The measured calorific values of the feedstocks were in good agreement with calculated values based on the Dulong equation, providing support for the accuracy of the elemental analysis. Calculated values based on biochemical composition were slightly lower value than the measured values.

\subsection{Mesophilic digestion}

The experiment ran for 296 days, equivalent to a cumulative total of 3.1 and 4.0 HRT based on the total volumes of feedstock added to digesters M1\&2 and M3\&4, respectively. Results for digestion performance are presented in Figure 1.

Biogas production started immediately on adding feed to the inoculum, and over the course of the experiment volumetric biogas production (VBP) (Figure 1a) mirrored changes in

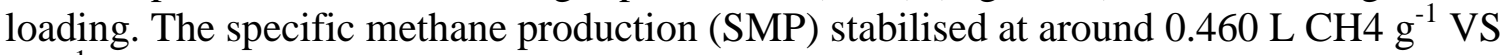
day $^{-1}$ (Figure 1b) although it was lower and less stable over the first 70 days of operation. Methane content varied between 55-60\%, with the lower percentage in the period between days 40-70. Although there appeared to be no long-term performance issues with acclimatisation a sharp increase in total VFA (TVFA) concentrations can be seen around day 40 (Figure 1c), which peaked at day 50 and had returned to baseline values by day 85 . This pattern has been noted several times in the past when using an inoculum from this source and switching to a new substrate [37]. The reason for it is unknown but its regularity of appearance has earned it the name 'the 40 day bump'. Individual VFA profiles are shown in Supplementary materials, and show that the VFA peaks were mainly composed of acetic acid with a small increase in iso-valeric concentrations. The increase in TVFA is mirrored by the sharp increase in the IA/PA ratio (Figure 1d), although the $\mathrm{pH}$ remained above 7 (Figure 1e) and finally stabilised around 7.9-8.0. As anticipated the TAN in the digestate increased (Figure 1f) reaching an equilibrium value of $\sim 4.5 \mathrm{~g} \mathrm{~L}^{-1}$ by day 290 . This provided strong buffering to the system and accounted for the elevated $\mathrm{pH}$ and high partial alkalinity (PA) which gradually increased from $4 \mathrm{~g} \mathrm{CaCO}_{3} \mathrm{~L}^{-1}$ at the beginning of the experiment to above 15 $\mathrm{g} \mathrm{CaCO}_{3} \mathrm{~L}^{-1}$ around day 130. The initial IA/PA ratio of $0.45-0.48$ decreased to $\leq 0.3$ even when the OLR was increased to 3 and $4 \mathrm{~g} \mathrm{VS} \mathrm{L}^{-1}$ day $^{-1}$, within the suggested range for stable digestion [27]. Digestate solids content had also stabilised by the end of the run, with a slightly higher proportion of VS as $\% \mathrm{TS}$ and $\% \mathrm{WW}$ in the digesters at the higher OLR (Figure $1 \mathrm{~g}$ and $\mathrm{h}$ ).

From day 70 all of the digesters had a high and reasonably stable gas production, low VFA and a low IA/PA ratio confirming that successful acclimatisation had occurred and the high$\mathrm{N}$ FW had no apparently toxic components. These results for mesophilic digestion of food waste are in good agreement with those of Banks et al. [15] and Zhang and Jahng [38].

\subsection{Thermophilic digestion}

\section{Acclimatisation to thermophilic conditions}

T1\&2 were fed with low-N FW and T3\&4 with high-N FW, but otherwise the conditions and feeding regime in these two pairs of digesters were the same. Temperature was raised on day 0 and feeding began on day 6 . The sudden increase in temperature is a shock to the system and this was reflected in the analytical results for process stability parameters over the following 60 days (Figure 2). SMP was initially low (Figure 2a) with a biogas methane content of around $20 \%$ (Figure $2 \mathrm{~b}$ ). Once substrate was added this was primarily converted to 
VFA (Figure 2c) which rose to between 3.5-5.0 $\mathrm{g} \mathrm{L}^{-1}$ irrespective of feed type. There was a corresponding increase in the IA/PA ratio (Figure $2 \mathrm{~d}$ ) in response to the VFA production, although the moderate rate of feed addition prevented the $\mathrm{pH}$ dropping to an inhibitory value (Figure 2e). From day 15 the digesters started to recover and this can be seen by the increase in biogas methane content (Figure 2b), the reduction in TVFA (Figure 2c), a fall in the IA/PA ratio (Figure 2d) and an increase in the SMP (Figure 2a). VS content in T3\&4 rose slightly but the VS/TS ratio in all four digesters remained similar (Figure $2 \mathrm{~g}$ and $\mathrm{h}$ ). By day 20 digestion appeared to be reasonably stable although the TVFA concentration fluctuated until around day 60: this may represent a thermophilic version of the '40 day bump', but other factors such as the temperature change and rising OLR are also present. Individual VFA profiles are shown in Supplementary materials, and are closely similar to those reported by Yirong et al. [36] for start-up on a similar FW feedstock. The only major deviation between the digesters over this period was in the TAN concentration (Figure $2 \mathrm{f}$ ) which gradually decreased in the low-N fed digesters T1 \& T2 and increased in the high-N fed digesters T3 \& T4. The results clearly showed that both pairs of digesters responded in a similar way to the heat shock and had acclimatised to the applied load by day 60 , with $\mathrm{pH}$ around neutral, IA/PA ratio between $0.4-0.5$ and TVFA generally below $500 \mathrm{mg} \mathrm{L}^{-1}$. These values are within the limits suggested by Ferrer et al. [39] who proposed the following to prevent failure in thermophilic digesters: acetic acid $<600 \mathrm{mg} \mathrm{L}^{-1}$, TVFA $<3700 \mathrm{mg} \mathrm{L}^{-1}$, intermediate alkalinity $<1800 \mathrm{mg} \mathrm{CaCO}_{3} \mathrm{~L}^{-1}, \mathrm{IA} / \mathrm{PA}<0.9$, and biogas methane content $>55 \%$.

\section{Thermophilic operation on low-N FW}

Figure 3 shows some key results over the 383-day operational period during which all performance and stability indicators settled within an acceptable range, with $\mathrm{pH}$ around 7.4 (Figure 3a), IA/PA ratio between 0.4-0.5 (Figure 3b), and TVFA generally below $500 \mathrm{mg} \mathrm{L}^{-1}$ (Figure 3c). There were some minor deviations: for example VBP was less stable for short periods around days 133 and 297 (Figure 3d), but this was due to short-term heater failures causing temporary cooling of the digesters, and production rapidly recovered when the operating temperature was restored. The average SMP in both T1 and T2 between days 283383 was $0.386 \mathrm{~L} \mathrm{CH}_{4} \mathrm{~g}^{-1} \mathrm{VS}$, corresponding to recovery of $85 \%$ of the measured calorific value as methane. The digestate VS concentration was around $2.5 \%$, corresponding to around $90 \%$ VS destruction of the low-N FW on a mass balance basis. It can be seen that the low-N feed allowed successful and stable long-term operation, and as 3 HRT had been achieved the digesters were considered to be in a suitable state for the $\mathrm{N}$ augmentation study using urea.

\section{Thermophilic operation on high-N FW}

Figure 4 shows the results over the experimental period for the pair of digesters fed on highN FW (T3\&4). The digesters began to show signs of stress as the TAN concentration rose above $\sim 2.5 \mathrm{~g} \mathrm{~N} \mathrm{~L}^{-1}$ (Figure $4 \mathrm{a}$ ) with both digesters showing a very rapid increase in VFA (Figure 4b) and a fall in specific methane production (Figure 4c). In an attempt to address this additional doses of selected trace elements (Table 1,11-element recipe) were added but without noticeable benefit. Digester T3 was more severely affected than T4: its VFA concentration had risen to $\sim 30 \mathrm{~g} \mathrm{~L}^{-1}$ before feeding was stopped on day 153 , by which time the $\mathrm{pH}$ had fallen to $<6.0$ and the biogas methane content to $<20 \%$ (Figure $4 \mathrm{~d}$ and e). The digester was considered to have failed by this point. It was, however, decided to try and recover it by re-seeding it using waste digestate from digesters T1, T2 and T4 to gradually dilute out the accumulated VFA and enrich the failed methanogenic population. Feeding of T3 started again on day 231 after a 78 -day pause, at which point the IA/PA ratio was around 0.5 . 
The feed to T4 continued uninterrupted and the rapid increase in TVFA peaked at $12 \mathrm{~g} \mathrm{~L}^{-1}$ on day 132 without breaking the buffering capacity of the digester, hence the $\mathrm{pH}$ did not fall to a point where methanogenesis was inhibited (Figure 4d). TVFA concentration fell over the next several days before starting to increase again from day 160 , but more gradually than before, reaching $\sim 19 \mathrm{~g} \mathrm{~L}^{-1}$ by day 279 . At this point there was again a very sharp increase in the rate of VFA accumulation with the concentration reaching $>33 \mathrm{~g} \mathrm{~L}^{-1}$ on day 307. This increase was sufficient to overcome the buffering capacity of the digestate and the $\mathrm{pH}$ dropped sharply to $<6$ by day 307 (Figure 4d) while the IA/PA ratio rose to 26.5 (Figure 4f). At this point the TAN in T4 had risen to $>5 \mathrm{~g} \mathrm{~N} \mathrm{~L}^{-1}$, and feeding to this digester was stopped on day 310. TVFA concentrations, however, continued to rise to a peak of $>46 \mathrm{~g} \mathrm{~L}^{-1}$ by day 325 before decreasing over the next 56 days to around $18 \mathrm{~g} \mathrm{~L}^{-1}$. This was a sufficient reduction to allow the $\mathrm{pH}$ to return to $>8$ and the IA/PA ratio to fall to 1.3 . On day 661 , however, almost a year after feeding had finished, the TVFA concentration was still $\sim 11 \mathrm{~g} \mathrm{~L}^{-1}$ (data not shown). The VFA profile (Figure 4h) shows the final rapid VFA accumulation to be in the form of acetic acid: this could be due to any of a range of factors, including inhibition of syntrophic acetate oxidisers, some of which are reported to be more sensitive than the methanogens to ammonia toxicity [40]. This acetic peak was subsequently removed after feeding ceased, but the 'fixed' VFA was propionic acid and its rate of removal was only very slow even under starvation conditions.

When feeding was resumed to digester T3 after a 78-day period of reseeding, a similar pattern of VFA accumulation was recommenced from day 231. A second sharp increase in TVFA occurred after the TVFA concentration reached about $18 \mathrm{~g} \mathrm{~L}^{-1}$ (Figure $4 \mathrm{~b}$ ), which again peaked at $45 \mathrm{~g} \mathrm{~L}^{-1}$ with an IA/PA ratio of 51.7. The final sharp rise in VFA could again be attributed to acetic acid accumulation (Figure 4g). Feeding was stopped on day 434 and the same pattern of partial recovery was seen as in T4, with a drop in acetic acid and a return to a $\mathrm{pH} 7$ with the IA/PA ratio falling to 0.9 . The results indicate that the period of reseeding did not help the population to acclimate and the point at which acetate conversion to methane failed was at around the same TAN concentration of $\sim 3.5 \mathrm{gL}^{-1}$. This value is similar to that reported by Hendriksen and Ahring [41] who showed initial inhibition between 3-4 $\mathrm{g} \mathrm{N} \mathrm{L}^{-1}$. TAN itself is not the most critical parameter, as the toxicity is due mainly to free ammonia and the equilibrium is $\mathrm{pH}$ and temperature dependent. In the current trial the $\mathrm{pH}$ in digesters T3 and T4 was about 8.0, and the FAN was thus in the same range as the $700-1100 \mathrm{mg} \mathrm{N} \mathrm{L}^{-1}$ inhibitory concentration suggested by Angelidaki and Ahring [42]. Methane production continued up until the point that the $\mathrm{pH}$ buffering capacity of the digester was broken and the $\mathrm{pH}$ dropped to a point known to be inhibitory to methanogens. It should be noted that the incremental accumulation of propionic and other longer chain VFA started after the TAN reached $\sim 2.5 \mathrm{~g} \mathrm{~L}^{-1}$ and indicates that the ammonia toxicity occurs through disruption of syntrophy.

\section{Effect of urea addition to low-N digesters}

In the first part of the trial the low-N digesters T1\&2 had shown a decreasing TAN concentration due to washout of the original inoculum TAN over 3 HRT, reaching a stable concentration by $\sim$ day 280 (Figure 5a). Urea addition began on day 384, with a single dose added to $\mathrm{T} 1$ to raise the TAN concentration to $\sim 2.5 \mathrm{~g} \mathrm{~N} \mathrm{~L}^{-1}$. There was then a slight decline, as no further urea was added while the reactor responded to this input and TAN washed out between day 385 and 464. Urea was then added incrementally as part of the daily feed to T1 to take the concentration to $\sim 3.5 \mathrm{~g} \mathrm{~N} \mathrm{~L}^{-1}$, and then finally added incrementally from day 700 to take the concentration to $\sim 4.2 . \mathrm{g} \mathrm{N} \mathrm{L}^{-1}$. In $\mathrm{T} 2$ no urea was added until day 441 , allowing 
this digester to act as a control against which the response of T1 to the shock load could be measured. Incremental urea addition then started and the TAN increased from that point to its target value of $2.5 \mathrm{~g} \mathrm{~N} \mathrm{~L}^{-1}$ which was reached around day 625 (Figure 5a). The TAN concentration was then increased incrementally from day 690 with a target of $3 \mathrm{~g} \mathrm{~N} \mathrm{~L}^{-1}$.

Calculated values for FAN based on the TAN, $\mathrm{pH}$ and digester temperature are shown in Figure $5 b$.

The response to these increases in TAN can be seen in the alkalinity and VFA profiles in Figure 5c and d. In T1 there was an immediate increase in VFA to around $4 \mathrm{~g} \mathrm{~L}^{-1}$ when the initial urea spike was added, which declined to $<0.5 \mathrm{~g} \mathrm{~L}^{-1}$ as the TAN concentration fell to $\sim 2.2 \mathrm{~g} \mathrm{~N} \mathrm{~L}^{-1}$. This VFA peak was buffered by the increased TAN, resulting in a rise in $\mathrm{pH}$ (Figure 5e) and there was little or no change in the IA/PA ratio which remained below 0.5, or in the SMP which continued at $\sim 0.38 \mathrm{~m}^{3} \mathrm{CH}_{4} \mathrm{~kg}^{-1} \mathrm{VS}$ (Figure 5f). Addition of urea in the feed to $\mathrm{T} 1$ from day 464 led to a gradual increase in TAN and once the concentration reached $\sim 2.5 \mathrm{~g} \mathrm{~N} \mathrm{~L}^{-1}$ VFA peaks of up to $3.3 \mathrm{~g} \mathrm{~L}^{-1}$ again began to appear. These were characterised by sharp increases in propionic acid, followed by even sharper falls (Figure 5g); acetic acid concentrations were also slightly elevated but the fluctuations were less pronounced. A slight reduction in TAN to below $3.5 \mathrm{~g} \mathrm{~N} \mathrm{~L}^{-1}$ between day 687-737 was accompanied by a fall in propionic acid concentration. When the TAN rose above $\sim 3.5 \mathrm{~g} \mathrm{~N} \mathrm{~L}^{-1}$ after day 750 the magnitude of the VFA peaks increased, and at a concentration of $4 \mathrm{~g} \mathrm{~N} \mathrm{~L}^{-1}$ there was no further decline in propionic acid and peaks in n- and iso-butyric appeared, along with a rise in iso-valeric concentration to around $0.8 \mathrm{~g} \mathrm{~L}^{-1}$. The appearance of longer chain VFA (C3 to C5 and above) indicates some blockage in the process of chain reduction and acetogenesis, as a direct or indirect effect of the increasing TAN concentration and its interaction with other digestion parameters.

The more gradual increase in TAN in digester T2 had no effect on total VFA concentration until the TAN reached around $2.5 \mathrm{~g} \mathrm{~N} \mathrm{~L}^{-1}$ when VFA peaks of $\sim 1 \mathrm{~g} \mathrm{~L}^{-1}$ began to appear, which were mainly composed of acetic acid (Figure $5 \mathrm{~h}$ ). A further increase in TAN concentration to around $3.0 \mathrm{~g} \mathrm{~N} \mathrm{~L}^{-1}$ led to an increase in VFA and the appearance of propionic acid peaks with the characteristic saw-tooth fluctuation observed in $\mathrm{T} 1$. This cyclic fluctuation could be due to the sensitivity of FAN to $\mathrm{pH}$ : as the VFA increases a small associated fall in $\mathrm{pH}$ may occur which shifts the ammonia equilibrium slightly away from the more toxic FAN. This in turn may reduce inhibition of methanogens and/or propionate degraders, causing a short-term fall in VFA and an increase in $\mathrm{pH}$ which subsequently leads to an increase in FAN and the start of the next cycle. Some support for this explanation is provided by Figure $5 \mathrm{~g}$ and $\mathrm{h}$ where peaks in VFA and FAN appear to be in anti-phase.

In both $\mathrm{T} 1$ and $\mathrm{T} 2$ digestate $\mathrm{pH}$ increased to around 7.8 in response to the urea addition (Figure 5e), while the average SMP showed little change (Figure 5f). The methane concentration in the biogas averaged around 54\% throughout the experiment, in agreement with the value predicted by the Buswell equation.

The results clearly showed the initial onset of instability when digester TAN concentrations reached $2.5 \mathrm{~g} \mathrm{~N} \mathrm{~L}^{-1}$, in agreement with the values obtained when using the high-N FW. There was no noticeable improvement in ammonia tolerance (i.e. no evidence of acclimatisation or adaptation in terms of digestion performance) in T2 despite the more gradual increase in TAN concentration, which remained around the lower threshold for onset of inhibition for over 100 days: a similar pattern of VFA accumulation is seen in T2 between 
days 700-830 in response to the increase in TAN and FAN concentrations as in T1 between days 390-470 after the shock increase in TAN. The digesters could, however, continue to perform without noticeable loss in SMP until the TAN concentration reached $3.5 \mathrm{~g} \mathrm{~N} \mathrm{~L}^{-1}$ where stability was seriously compromised, characterised by a sharp increase in acetic acid and an irreversible increase in the concentration of longer chain length VFA.

\subsection{Energy conversion efficiency}

Measured BMP values are shown in Table 5 and compared with theoretical BMP values from the Buswell equation and equivalent CVs; values for VS destruction are also shown. In the BMP test, the calorific value of the methane produced by the high-N FW was $18.8 \mathrm{~kJ} \mathrm{~g}^{-1} \mathrm{VS}$, equal to $81 \%$ of the measured $\mathrm{CV}$; the equivalent values for low-N FW were $15.6 \mathrm{~kJ} \mathrm{~g}^{-1} \mathrm{VS}$ and $87 \%$, reflecting its lower protein and lipid content but slightly higher degradability. In the mesophilic digestion trial with high-N FW the SMP achieved was only slightly lower than the BMP value, equivalent to around $79 \%$ of the measured CV and $97 \%$ of the BMP, again confirming the rapid degradability and good energy yield of this substrate. The high percentage of BMP may also reflect the long retention time at this OLR. The value of $79 \%$ of $\mathrm{CV}$ also corresponds well to the VS destruction of around $81 \%$ and to the $81 \%$ of ThMP for M3 and M4. In thermophilic conditions the SMP for high-N FW was lower and less consistent, averaging around $70 \%$ of measured CV for $\mathrm{T} 3$ and $75 \%$ for $\mathrm{T} 4$ during periods of apparent stability. Many authors have suggested that thermophilic digestion may give higher methane yields than mesophilic. For the current FW, however, the results indicate that even if the potential for degradation is higher in thermophilic conditions, this is not sufficient to make up for the inhibitory effects of TAN, as indicated by the relative proportions of BMP, ThMP and measured CV achieved in the mesophilic and thermophilic trials with high-N FW (Table 5).

For the low-N FW the SMP in thermophilic conditions was around $85 \%$ of the measured CV, in reasonable agreement with the VS destruction of $\sim 90 \%$. The SMP of $15.6 \mathrm{~kJ} \mathrm{~g}^{-1} \mathrm{VS}$ was over $98 \%$ of the measured BMP value of $15.6 \mathrm{~kJ} \mathrm{~g}^{-1} \mathrm{VS}$ added. As the BMP test was conducted in mesophilic conditions this could indicate slightly greater conversion at $55{ }^{\circ} \mathrm{C}$. In general the results confirm the very high degree of conversion and energy recovery achievable with substrates of this type. More details of the BMP test and results are given in Supplementary materials.

\subsection{Discussion}

The results clearly show that acclimatisation of a mesophilic inoculum to thermophilic conditions can reach a stable state in a period of less than 60 days, and the approach used of a step increase in temperature was an effective alternative to the step-wise changes in temperature that are sometimes recommended [43]. The sharp rise in VFA early in the acclimatisation process is a strong indication that the load in the early stages must be moderated to ensure that $\mathrm{pH}$ does not fall below a critical value. The pattern of acclimatisation between two quite dissimilar feedstocks (low and high-N) was remarkably similar. The high-N FW was readily digestible in mesophilic conditions indicating that the substrate itself was not likely to be inhibitory to the digestion process, which could tolerate a digestate TAN concentration of at least $4.5 \mathrm{~g} \mathrm{~N} \mathrm{~L}^{-1}$, equivalent to a FAN of $0.45 \mathrm{~g} \mathrm{~N} \mathrm{~L}^{-1}$. Unfortunately the range of tolerances quoted in a recent review [20] is so wide that comparison is difficult, especially given the many different substrates that have been used. The current result is very similar to that in previous work carried out using this type of 
substrate in mesophilic conditions where TAN concentrations as high as $5.4 \mathrm{~g} \mathrm{~N} \mathrm{~L}^{-1}$ have been tolerated without significant loss of performance [15]. The digesters fed on low-N FW stabilised at a very low TAN concentration and were never in danger from ammonia toxicity. Ammonia toxicity thresholds in thermophilic conditions have been reported for a number of different substrates, with general agreement that these are below values seen in mesophilic systems. Hashimoto [44] observed that ammonia inhibition began at about $2.5 \mathrm{~g} \mathrm{~N} \mathrm{~L}^{-1}$ and $4 \mathrm{~g}$ $\mathrm{N} \mathrm{L}^{-1}$ for unacclimatised and acclimatised thermophilic methanogens, respectively, and a number of other studies have demonstrated acclimatisation is possible [42, 45-47]; but it is unclear whether this is as a result of a metabolic transition in the existing microbial population or from the growth of new cultures adapted to different ammonia concentrations [19]. In the current work, no real evidence of adaptation or acclimatisation was seen in the digestion performance despite the prolonged operating periods at high TAN concentrations.

The work using low-N FW with urea addition clearly established the threshold concentrations where instability could be observed $\left(2.5 \mathrm{~g} \mathrm{~N} \mathrm{~L}^{-1}\right)$ and the critical point at which irreversible failure was likely at a TAN $3.5 \mathrm{~g} \mathrm{~N} \mathrm{~L}^{-1}$, equivalent to a FAN concentration of $0.85 \mathrm{~g} \mathrm{~N} \mathrm{~L}^{-1}$. The TAN and FAN concentrations for this critical point were almost identical for both the high-N FW and the urea-supplemented low-N FW, despite the contrasting strategies of shock loading versus slow accumulation, and again no evidence of adaptation or acclimatisation was observed in the digestion performance.

This study is believed to be one of the first to identify different inhibition thresholds, from the onset of mild instability through to progressive failure, and to suggest an explanation for the phenomenon of saw-tooth VFA profiles observed in meta-stable conditions below the critical TAN and FAN concentrations for progressive VFA accumulation. The results thus contribute towards clarifying the wide range of inhibition values quoted in previous literature.

\section{Conclusions}

The mesophilic digestion of a source segregated domestic food waste with a typical 'high' nitrogen content was possible without any signs of system instability or loss of performance at increasing loadings. There was clearly no component of the food waste itself which under these conditions was toxic or inhibitory to the anaerobic process. A step change in temperature from mesophilic to thermophilic temperatures followed by a period of starvation and then a gradual increase in load was shown to be an effective means of acclimating to thermophilic conditions. Running digesters on high-N FW without dilution was not, however, possible in the long term. Although gas production continued even at high VFA concentrations, the increase in VFA eventually overcame the buffering capacity, resulting in a rapid decrease in $\mathrm{pH}$ and catastrophic failure. Very sharp increases in VFA concentration were observed as the TAN concentration exceeded $3.5 \mathrm{~g} \mathrm{~N} \mathrm{~L}^{-1}$ and, although this could be partially overcome in the short term, there was no long term solution to the accumulation of propionic acid. It was possible to run the digesters over long periods on a low-N FW with good methane production and VS destruction. Raising the TAN of this feed material with urea provided a method of establishing the critical TAN concentration. The results showed it was possible to operate without significant VFA accumulation at a TAN concentration of $\leq$ $2.5 \mathrm{~g} \mathrm{~N} \mathrm{~L}^{-1}$ but propionic acid started to appear as the TAN rose above $3.0 \mathrm{~g} \mathrm{~N} \mathrm{~L}^{-1}$ and showed irreversible accumulation at a concentration of $3.5 \mathrm{~g} \mathrm{~N} \mathrm{~L}^{-1}$. Digester failure was as a result of the $\mathrm{pH}$ buffering capacity of the digester being broken causing a rapid fall in $\mathrm{pH}$ to sub-optimal conditions for methanogens. This fall was preceded by a sharp increase in acetic acid concentration indicating that all routes for conversion of acetate to methane were 
compromised. The steady accumulation of proprionate and other longer chain VFA indicated that ammonia also inhibits the syntrophy between methanogens and acetogens. Despite different strategies for increasing the ammonia concentration, applied in over relatively long periods, no clear sign of adaptation or acclimatisation was seen in terms of the overall digestion performance.

\section{Acknowledgements}

Thanks are due to the Government of Thailand for research studentship funding, and to the EU FP7 VALORGAS Project (241334, www.valorgas.soton.ac.uk) for additional support.

\section{References}

[1] D. Barnes, C. F. Forster, and S. E. Hrudey, "Survey in industrial wastewater treatment: food and allied industries," in Survey in industrial wastewater treatment: food and allied industries, ed: Pitman Advanced Publ. Program, 1984.

[2] G. Capson-Tojo, M. Rouez, M. Crest, J.-P. Steyer, J.-P. Delgenès, and R. Escudié, "Food waste valorization via anaerobic processes: a review," Reviews in Environmental Science and Bio/Technology, vol. 15, pp. 499-547, 2016.

[3] C. J. Banks, M. Chesshire, and A. Stringfellow, "A pilot-scale comparison of mesophilic and thermophilic digestion of source segregated domestic food waste," Water science and technology, vol. 58, pp. 1475-1481, 2008.

[4] M. Chesshire, "The South Shropshire biowaste digester, UK," Proceedings of the Institution of Civil Engineers-Waste and Resource Management, vol. 160, pp. 19-26, 2007.

[5] S. Grimberg, D. Hilderbrandt, M. Kinnunen, and S. Rogers, "Anaerobic digestion of food waste through the operation of a mesophilic two-phase pilot scale digesterassessment of variable loadings on system performance," Bioresource technology, vol. 178, pp. 226-229, 2015.

[6] S. Y. Xu, H. P. Lam, O. P. Karthikeyan, and J. W. Wong, "Optimization of food waste hydrolysis in leach bed coupled with methanogenic reactor: effect of $\mathrm{pH}$ and bulking agent," Bioresource technology, vol. 102, pp. 3702-3708, 2011.

[7] J. D. Browne, E. Allen, and J. D. Murphy, "Improving hydrolysis of food waste in a leach bed reactor," Waste management, vol. 33, pp. 2470-2477, 2013.

[8] A. Bernstad, L. Malmquist, C. Truedsson, and J. la Cour Jansen, "Need for improvements in physical pretreatment of source-separated household food waste," Waste management, vol. 33, pp. 746-754, 2013.

[9] L. Deng, Y. Liu, D. Zheng, L. Wang, X. Pu, L. Song, et al., "Application and development of biogas technology for the treatment of waste in China," Renewable and Sustainable Energy Reviews, 2016.

[10] ADBA, "Anaerobic Digestion Market Report," Anaerobic Digestion and Bioresources Association2016.

[11] C. Neiva Correia, F. Vaz, A. Torres, and C. Dinis de Souza, "Valorsul's experience in the operation of the anaerobic digestion plant for source collected biodegradable waste," presented at the ISWA World Congress, Lisbon, 2009.

[12] W. Zhang, S. Heaven, and C. J. Banks, "Thermophilic digestion of food waste by dilution: ammonia limit values and energy considerations," Energy \& Fuels, 2017.

[13] W. Zhang, S. Heaven, and C. J. Banks, "Continuous operation of thermophilic food waste digestion with side-stream ammonia stripping," Bioresource Technology, vol. 244, pp. 611-620, 2017. 
[14] Y. Park, F. Hong, J. Cheon, T. Hidaka, and H. Tsuno, "Comparison of thermophilic anaerobic digestion characteristics between single-phase and two-phase systems for kitchen garbage treatment," Journal of bioscience and bioengineering, vol. 105, pp. 48-54, 2008.

[15] C. J. Banks, Y. Zhang, Y. Jiang, and S. Heaven, "Trace element requirements for stable food waste digestion at elevated ammonia concentrations," Bioresource technology, vol. 104, pp. 127-135, 2012.

[16] Y. Zhang, C. J. Banks, and S. Heaven, "Anaerobic digestion of two biodegradable municipal waste streams," Journal of environmental management, vol. 104, pp. 166174, 2012.

[17] C. Neiva Correia, F. Vaz, and A. Torres, "Anaerobic digestion of biodegradable waste-operational and stability parameters for stability control," in 5th IWA International Symposium on AD of Solid Wastes and Energy Crops, Tunisia, 2008.

[18] Y. Chen, J. J. Cheng, and K. S. Creamer, "Inhibition of anaerobic digestion process: a review," Bioresource technology, vol. 99, pp. 4044-4064, 2008.

[19] R. Rajagopal, D. I. Massé, and G. Singh, "A critical review on inhibition of anaerobic digestion process by excess ammonia," Bioresource Technology, vol. 143, pp. 632641, 2013.

[20] O. Yenigün and B. Demirel, "Ammonia inhibition in anaerobic digestion: a review," Process Biochemistry, vol. 48, pp. 901-911, 2013.

[21] D. Karakashev, D. J. Batstone, and I. Angelidaki, "Influence of environmental conditions on methanogenic compositions in anaerobic biogas reactors," Applied and environmental microbiology, vol. 71, pp. 331-338, 2005.

[22] J. De Vrieze, A. M. Saunders, Y. He, J. Fang, P. H. Nielsen, W. Verstraete, et al., "Ammonia and temperature determine potential clustering in the anaerobic digestion microbiome," Water research, vol. 75, pp. 312-323, 2015.

[23] L. Guerrero, F. Omil, R. Mendez, and J. Lema, "Anaerobic hydrolysis and acidogenesis of wastewaters from food industries with high content of organic solids and protein," Water Research, vol. 33, pp. 3281-3290, 1999.

[24] I. Angelidaki, X. Chen, J. Cui, P. Kaparaju, and L. Ellegaard, "Thermophilic anaerobic digestion of source-sorted organic fraction of household municipal solid waste: start-up procedure for continuously stirred tank reactor," Water research, vol. 40, pp. 2621-2628, 2006.

[25] M. Walker, Y. Zhang, S. Heaven, and C. Banks, "Potential errors in the quantitative evaluation of biogas production in anaerobic digestion processes," Bioresource Technology, vol. 100, pp. 6339-6346, 2009.

[26] APHA, Standard methods for the examination of water and wastewater, 21st ed. Washington, DC, USA: American Public Health Association, American Water Works Association, Water Environment Federation, 2005.

[27] L. Ripley, W. Boyle, and J. Converse, "Improved alkalimetric monitoring for anaerobic digestion of high-strength wastes," Journal (Water Pollution Control Federation), pp. 406-411, 1986.

[28] A. Sluiter, B. Hames, R. Ruiz, C. Scarlata, J. Sluiter, D. Templeton, et al., "Determination of structural carbohydrates and lignin in biomass," Laboratory analytical procedure, vol. 1617, pp. 1-16, 2008.

[29] US-EPA, "Method 9071B: n-hexane extractable material (HEM) for sludge, sediment and solid samples. Test methods for evaluation solid waste, Physical / Chemical methods, SW-846.," ed: United States Environmental Protection Agency, 1998.

[30] ISO, "6878 Water Quality - Determination of phosphorus - Ammonium molybdate spectrometric method," ed: International Organization for Standardization, 2004. 
[31] M. Kitcherside, E. Glen, and A. Webster, "Fibrecap: an improved method for the rapid analysis of fibre in feeding stuffs," Animal Feed Science and Technology, vol. 86, pp. 125-132, 2000.

[32] K. H. Hansen, I. Angelidaki, and B. K. Ahring, "Anaerobic digestion of swine manure: inhibition by ammonia," Water research, vol. 32, pp. 5-12, 1998.

[33] IFRF, "Method from Combustion File 24," in Online Combustion Handbook, ed: International Flame Research Foundation, 2017.

[34] I. Angelidaki and W. Sanders, "Assessment of the anaerobic biodegradability of macropollutants," Reviews in Environmental Science and Biotechnology, vol. 3, pp. 117-129, 2004.

[35] A. Buswell and H. Mueller, "Mechanism of methane fermentation," Industrial \& Engineering Chemistry, vol. 44, pp. 550-552, 1952.

[36] C. Yirong, S. Heaven, and C. Banks, "Effect of a trace element addition strategy on volatile fatty acid accumulation in thermophilic anaerobic digestion of food waste," Waste and Biomass Valorization, vol. 6, pp. 1-12, 2015.

[37] Y. Zhang, C. J. Banks, and S. Heaven, "Co-digestion of source segregated domestic food waste to improve process stability," Bioresource technology, vol. 114, pp. 168$178,2012$.

[38] L. Zhang and D. Jahng, "Long-term anaerobic digestion of food waste stabilized by trace elements," Waste Management, vol. 32, pp. 1509-1515, 2012.

[39] I. Ferrer, F. Vázquez, and X. Font, "Long term operation of a thermophilic anaerobic reactor: process stability and efficiency at decreasing sludge retention time," Bioresource technology, vol. 101, pp. 2972-2980, 2010.

[40] H. Wang, I. A. Fotidis, and I. Angelidaki, "Ammonia effect on hydrogenotrophic methanogens and syntrophic acetate-oxidizing bacteria," FEMS microbiology ecology, vol. 91, p. fiv130, 2015.

[41] H. V. Hendriksen and B. K. Ahring, "Effects of ammonia on growth and morphology of thermophilic hydrogen-oxidizing methanogenic bacteria," FEMS Microbiology Letters, vol. 85, pp. 241-245, 1991.

[42] I. Angelidaki and B. Ahring, "Anaerobic thermophilic digestion of manure at different ammonia loads: effect of temperature," Water Research, vol. 28, pp. 727-731, 1994.

[43] A. Boušková, M. Dohanyos, J. E. Schmidt, and I. Angelidaki, "Strategies for changing temperature from mesophilic to thermophilic conditions in anaerobic CSTR reactors treating sewage sludge," Water Research, vol. 39, pp. 1481-1488, 2005.

[44] A. G. Hashimoto, "Ammonia inhibition of methanogenesis from cattle wastes," Agricultural Wastes, vol. 17, pp. 241-261, 1986.

[45] R. Borja, E. Sánchez, and P. Weiland, "Influence of ammonia concentration on thermophilic anaerobic digestion of cattle manure in upflow anaerobic sludge blanket (UASB) reactors," Process Biochemistry, vol. 31, pp. 477-483, 1996.

[46] C. Gallert and J. Winter, "Mesophilic and thermophilic anaerobic digestion of sourcesorted organic wastes: effect of ammonia on glucose degradation and methane production," Applied microbiology and biotechnology, vol. 48, pp. 405-410, 1997.

[47] S. Sung and T. Liu, "Ammonia inhibition on thermophilic anaerobic digestion," Chemosphere, vol. 53, pp. 43-52, 2003. 
Table 1 Trace element solutions

\begin{tabular}{lcccc}
\hline Cations & Compound used & $\begin{array}{c}\text { Compound } \\
\text { concentration in } \\
\text { stock solution, g L }\end{array}$ & $\begin{array}{c}\text { TE concentration in 5 and } \\
\text { stock solutions, g L }\end{array}$ \\
\hline Aluminium (Al) & $\mathrm{AlCl}_{3} \cdot 6 \mathrm{H}_{2} \mathrm{O}$ & 0.895 & - & 5-element \\
Boron (B) & $\mathrm{H}_{3} \mathrm{BO}_{3}$ & 0.572 & - & 0.1 \\
Cobalt (Co) & $\mathrm{CoCl}_{2} \cdot 6 \mathrm{H}_{2} \mathrm{O}$ & 4.038 & 1.0 & 1.0 \\
Copper (Cu) & $\mathrm{CuCl}_{2} \cdot 2 \mathrm{H}_{2} \mathrm{O}$ & 0.268 & - & 0.1 \\
Iron (Fe) & $\mathrm{FeCl}_{2} \cdot 4 \mathrm{H}_{2} \mathrm{O}$ & 35.597 & - & 10.0 \\
Manganese (Mn) & $\mathrm{MnCl}_{2} \cdot 6 \mathrm{H}_{2} \mathrm{O}$ & 4.258 & - & 1.0 \\
Nickel (Ni) & $\mathrm{NiCl}_{2} \cdot 6 \mathrm{H}_{2} \mathrm{O}$ & 4.050 & 1.0 & 1.0 \\
Zinc (Zn) & $\mathrm{ZnCl}_{2}$ & 0.417 & - & 0.2 \\
Oxyanions & & & & \\
Molybdenum (Mo) & $\left(\mathrm{NH}_{4}\right)_{6} \mathrm{Mo}_{7} \mathrm{O}_{24} \cdot 4 \mathrm{H}_{2} \mathrm{O}$ & 0.368 & 0.2 & 0.2 \\
Selenium (Se) & $\mathrm{Na}_{2} \mathrm{SeO}_{3}$ & 0.438 & 0.2 & 0.2 \\
Tungsten (W) & $\mathrm{Na}_{2} \mathrm{WO}_{4} 2 \mathrm{H}_{2} \mathrm{O}$ & 0.359 & 0.2 & 0.2 \\
\hline
\end{tabular}


Table 2 Planned operating conditions during experimental period

\begin{tabular}{|c|c|c|c|c|}
\hline & Day & M1\&2 & M3\&4 & \\
\hline Feedstock & & high-N FW & high-N FW & \\
\hline Temp ${ }^{\circ} \mathrm{C}$ & & 37 & 37 & \\
\hline OLR & $0-97$ & 2 & 2 & - \\
\hline$\left(\mathrm{g} \mathrm{VS} \mathrm{L}^{-1}\right.$ & $98-116$ & 2 & 2 to 3 & - \\
\hline \multirow[t]{4}{*}{ day $\left.^{-1}\right)$} & $117-176$ & 2 & 3 & - \\
\hline & $177-209$ & 2 to 3 & 3 to 4 & - \\
\hline & $210-296$ & 3 & 4 & - \\
\hline & & $\mathrm{T} 1$ & $\mathrm{~T} 2$ & T3\&4 \\
\hline Feedstock & & low-N FW & low-N FW & high-N FW \\
\hline Temp ${ }^{\circ} \mathrm{C}$ & & 55 & 55 & 55 \\
\hline OLR & $0-6$ & 0 & 0 & 0 \\
\hline$\left(\mathrm{g} \mathrm{VS} \mathrm{L}^{-1}\right.$ & $7-39$ & 0.5 to 2 & 0.5 to 2 & 0.5 to 2 \\
\hline day $\left.^{-1}\right)$ & 40 on & 2 & 2 & 2 \\
\hline Urea: & 384 & 2.5 & 0 & - \\
\hline Target & 441 on & - & 0 to 2.5 & - \\
\hline TAN & 464 on & 2.5 to 3.5 & 0 to 2.5 & - \\
\hline$\left(\mathrm{g} \mathrm{N} \mathrm{L}^{-1}\right)$ & 750 on & 4 & 3 & - \\
\hline
\end{tabular}


Table 3 Food waste characteristics

\begin{tabular}{|c|c|c|}
\hline Parameter & $\begin{array}{c}\text { Source segregated } \\
\text { kerbside collected } \\
\text { domestic food waste }\end{array}$ & $\begin{array}{l}\text { low-N synthetic } \\
\text { food waste }\end{array}$ \\
\hline \multicolumn{3}{|c|}{ Basic characteristics for anaerobic digestion } \\
\hline TS (\% wet weight) & 23.91 & 22.48 \\
\hline VS (\% wet weight) & 21.64 & 21.88 \\
\hline $\mathrm{VS}(\% \mathrm{TS})$ & 90.51 & 97.33 \\
\hline \multicolumn{3}{|c|}{ Nutrients value as fertiliser substitute } \\
\hline TKN (\% TS) & 3.09 & 1.45 \\
\hline $\mathrm{TP}(\mathrm{P})\left(\mathrm{g} \mathrm{kg}^{-1} \mathrm{TS}\right)$ & 3.80 & - \\
\hline $\mathrm{TK}(\mathrm{K})\left(\mathrm{g} \mathrm{kg}^{-1} \mathrm{TS}\right)$ & 12.87 & - \\
\hline \multicolumn{3}{|c|}{ Essential trace elements (mg $\left.\mathrm{kg}^{-1} \mathrm{TS}\right)$} \\
\hline Cobalt (Co) & 0.086 & $* \mathrm{ND}$ \\
\hline Iron $(\mathrm{Fe})$ & 121.1 & 38.2 \\
\hline Manganese (Mn) & 90.05 & - \\
\hline Molybdenum (Mo) & 0.506 & 0.23 \\
\hline Selenium (Se) & 0.127 & $* \mathrm{ND}$ \\
\hline Tungsten (W) & $<0.015$ & - \\
\hline \multicolumn{3}{|c|}{ Biochemical composition ( $\mathrm{g} \mathrm{kg}^{-1} \mathrm{VS}$ ) } \\
\hline Carbohydrates & 525 & 555 \\
\hline Lipids & 151 & 13 \\
\hline Crude proteins & 213 & 91 \\
\hline Hemi-cellulose & 66 & 49 \\
\hline Cellulose & 68 & 324 \\
\hline Lignin & 16 & 5 \\
\hline \multicolumn{3}{|l|}{ Elemental analysis(\%VS) } \\
\hline $\mathrm{C}$ & 54.89 & 47.52 \\
\hline $\mathrm{H}$ & 6.89 & 6.94 \\
\hline $\mathrm{N}$ & 3.32 & 1.02 \\
\hline $\mathrm{S}$ & 0.25 & - \\
\hline \multicolumn{3}{|l|}{ Calorific Value $\left(\mathrm{kJ}^{-1} \mathrm{VS}\right)$} \\
\hline Measured CV & 23.2 & 18.0 \\
\hline Calculated CV (Du Long) & 22.6 & 19.0 \\
\hline Calculated CV (Biochemical) & 21.2 & 17.8 \\
\hline
\end{tabular}

*ND: not detected 
Table 4 Mesophilic inoculum characteristics

\begin{tabular}{lc}
\hline Parameters & Value \\
\hline $\mathrm{pH}$ & 7.26 \\
$\mathrm{TS}(\%$ wet weight) & 3.46 \\
$\mathrm{VS}(\%$ wet weight) & 2.31 \\
$\mathrm{TAN}\left(\mathrm{mg} \mathrm{N} \mathrm{kg}^{-1}\right.$ wet weight) & 1393 \\
Total alkalinity (mg kg wet weight as $\left.\mathrm{CaCO}_{3}\right)$ & 7027 \\
Intermediate alkalinity (mg kg wet weight as $\left.\mathrm{CaCO}_{3}\right)$ & 2238 \\
Partial alkalinity (mg kg & 4789 \\
Total VFA (mg Let weight as $\left.\mathrm{CaCO}_{3}\right)$ & 53
\end{tabular}


Table 5 Energy recovery values for methane production from low-N and high-N FW

\begin{tabular}{|c|c|c|c|c|c|c|}
\hline & $\mathrm{LCH}_{4} \mathrm{~g}^{-1} \mathrm{VS}$ & $\begin{array}{l}\mathrm{kJ} \mathrm{g}^{-1} \\
\mathrm{VS}\end{array}$ & $\% \mathrm{BMP}$ & $\%$ ThMP & $\begin{array}{c}\% \\
\text { measured } \\
\mathrm{CV}\end{array}$ & $\begin{array}{c}\% \mathrm{VS} \\
\text { destruction }\end{array}$ \\
\hline \multicolumn{7}{|l|}{ High-N FW } \\
\hline ThMP $^{\mathrm{a}}$ & 0.563 & 22.4 & - & - & - & - \\
\hline BMP & 0.473 & 18.8 & - & $84.0 \%$ & $81.2 \%$ & - \\
\hline SMP mesophilic & 0.460 & 18.3 & $97.2 \%$ & $81.7 \%$ & $78.9 \%$ & $81.2 \%$ \\
\hline SMP thermo $-\mathrm{T} 3^{\mathrm{b}}$ & 0.408 & 16.3 & $86.3 \%$ & $72.5 \%$ & $70.1 \%$ & - \\
\hline SMP thermo $-\mathrm{T} 4^{\mathrm{b}}$ & 0.436 & 17.4 & $92.2 \%$ & $77.4 \%$ & $74.9 \%$ & - \\
\hline \multicolumn{7}{|l|}{ Low-N FW } \\
\hline ThMP $^{\mathrm{a}}$ & 0.476 & 19.0 & - & - & - & - \\
\hline BMP & 0.392 & 15.6 & - & $82.4 \%$ & $86.8 \%$ & - \\
\hline SMP thermo - $1^{b}$ & 0.386 & 15.4 & $98.4 \%$ & $81.0 \%$ & $85.4 \%$ & $90.6 \%$ \\
\hline SMP thermo - T2 ${ }^{\mathrm{b}}$ & 0.386 & 15.4 & $98.4 \%$ & $81.0 \%$ & $85.4 \%$ & $91.0 \%$ \\
\hline
\end{tabular}



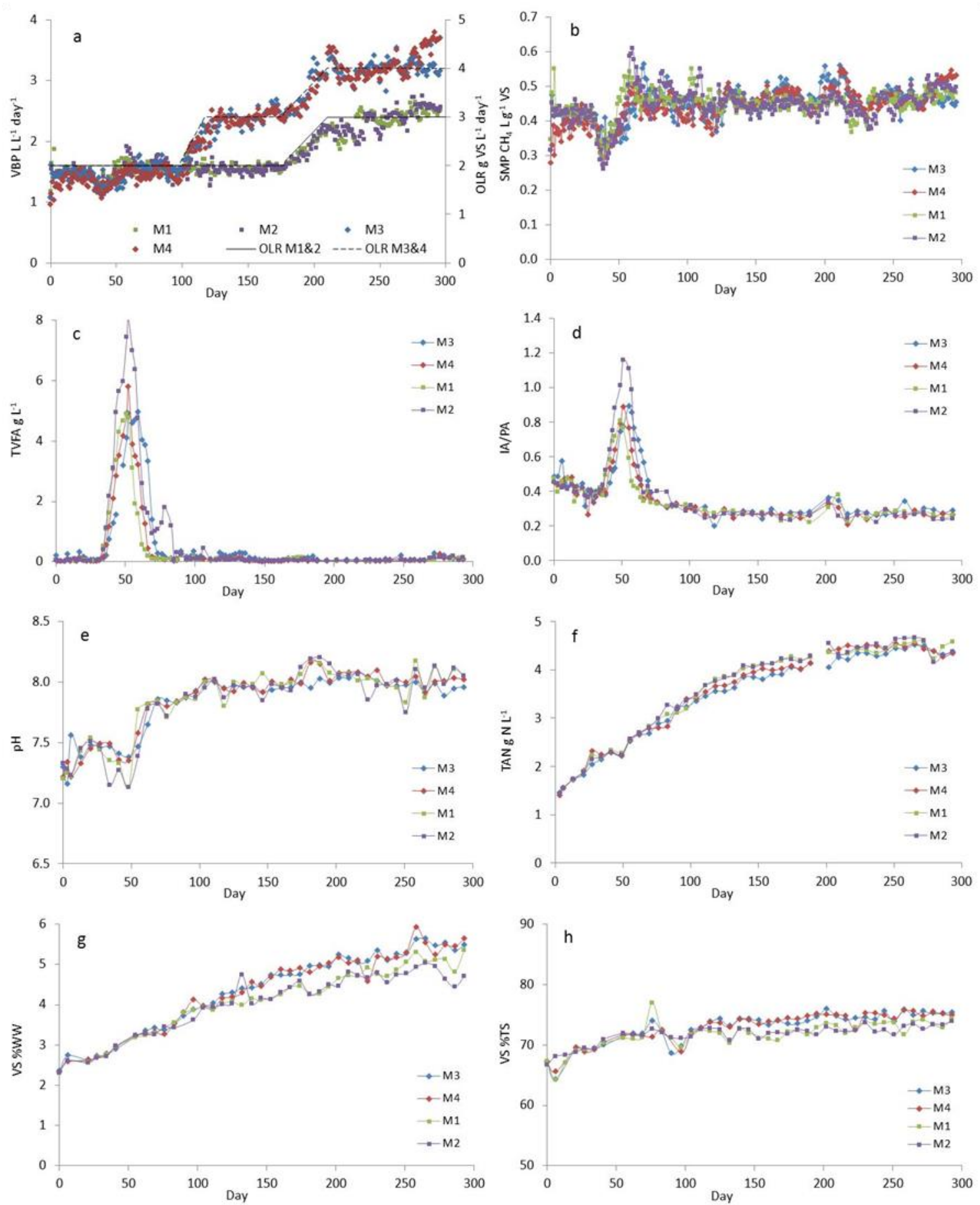

Figure 1 Selected monitoring parameters during mesophilic digestion of high-N FW. (a) VBP, (b) SMP, (c) TVFA (d) IA/PA ratio, (e) pH, (f) TAN content, (g) VS \%WW (h) VS $\%$ TS. Vertical dotted lines indicate changes in OLR as noted in Table 2. 

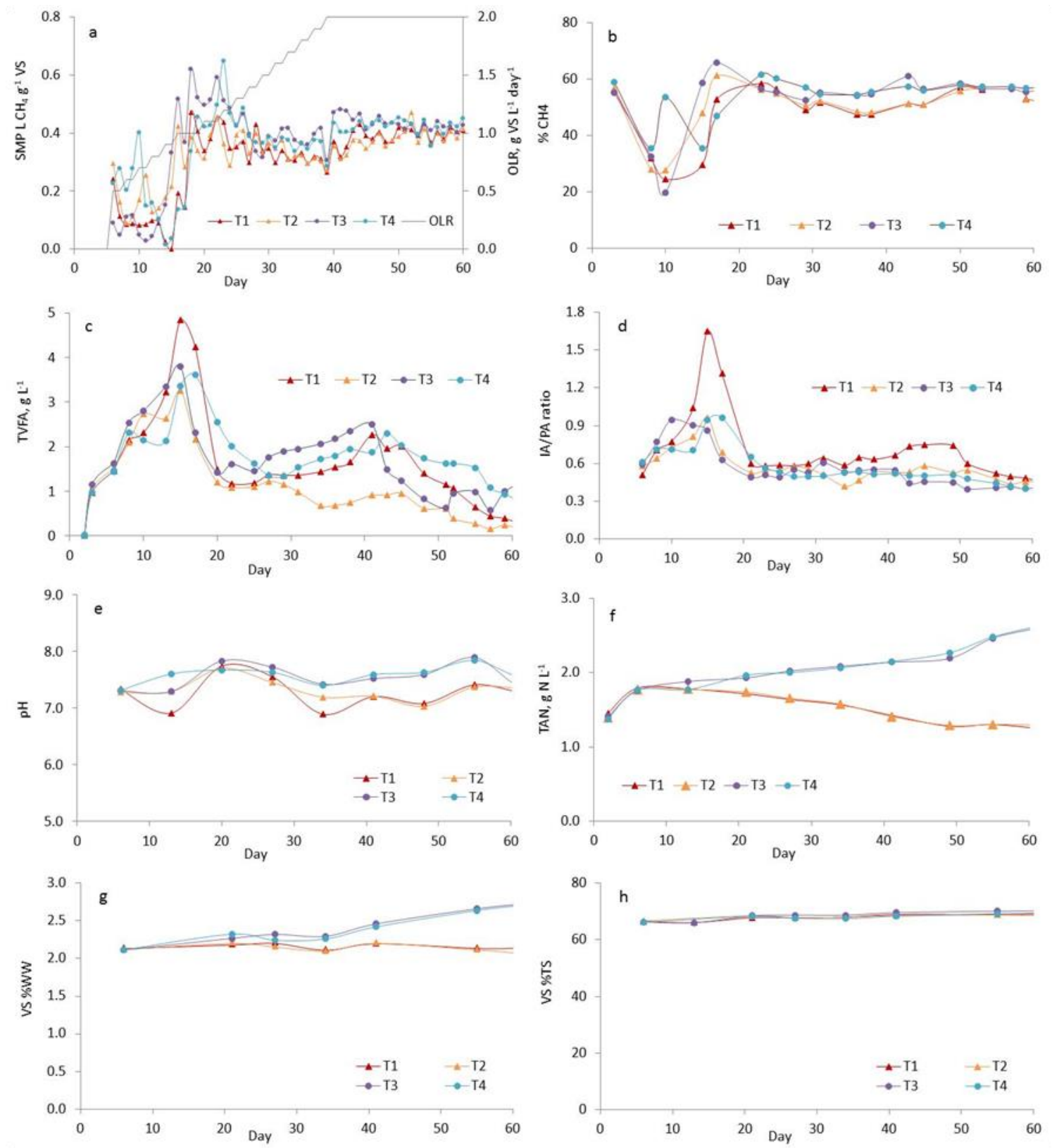

Figure 2 Selected monitoring parameters during acclimatisation of thermophilic digesters (day 0-60) (a) SMP, (b) biogas methane content, (c) TVFA (d) IA/PA ratio, (e) pH, (f) TAN, (g) VS as \%WW and (h) VS as \%TS. 

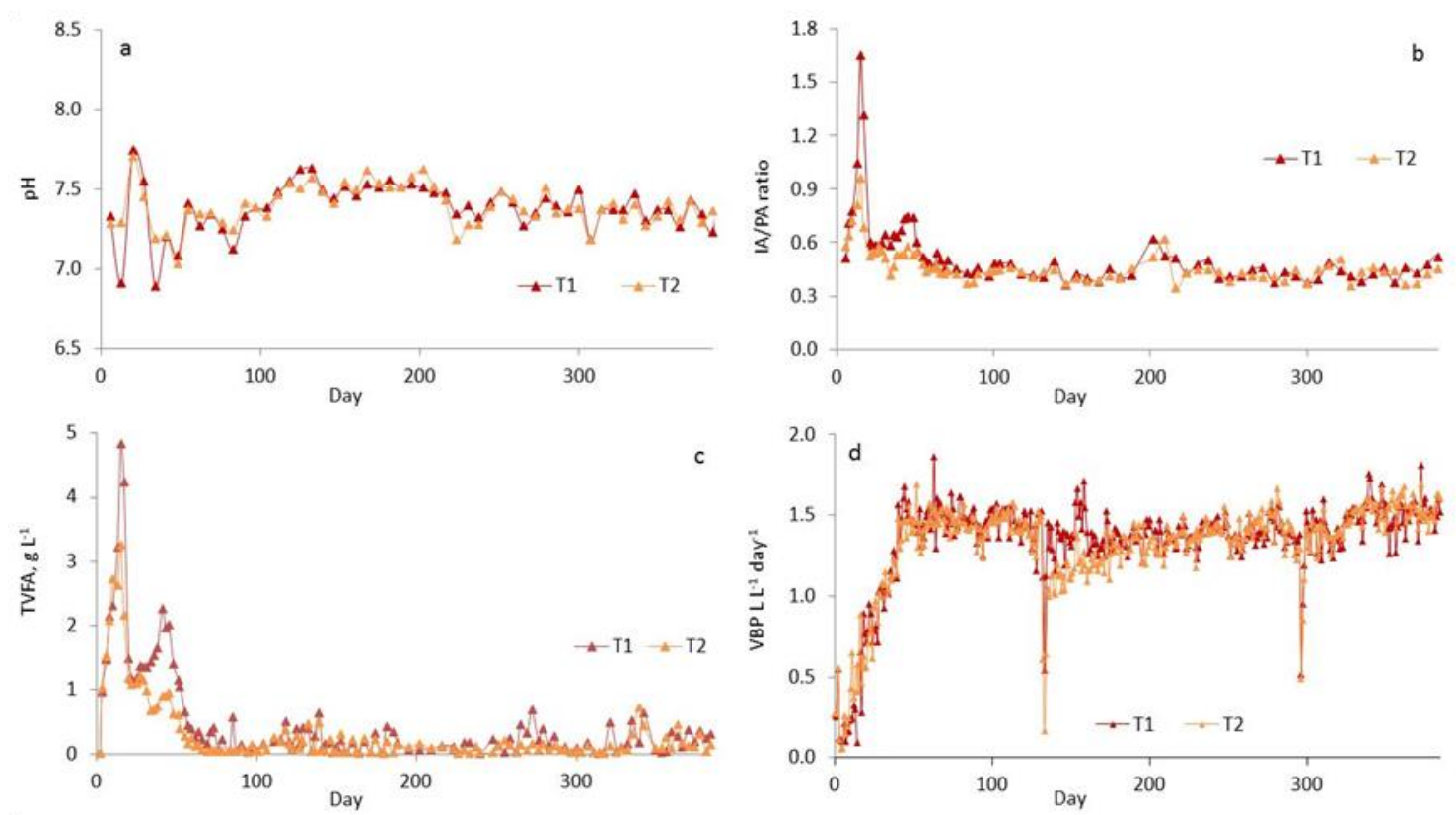

Figure 3 Selected monitoring parameters during thermophilic digestion of low-N FW. (a) $\mathrm{pH}$, (b) IA/PA ratio, (c) TVFA (d) VBP. 

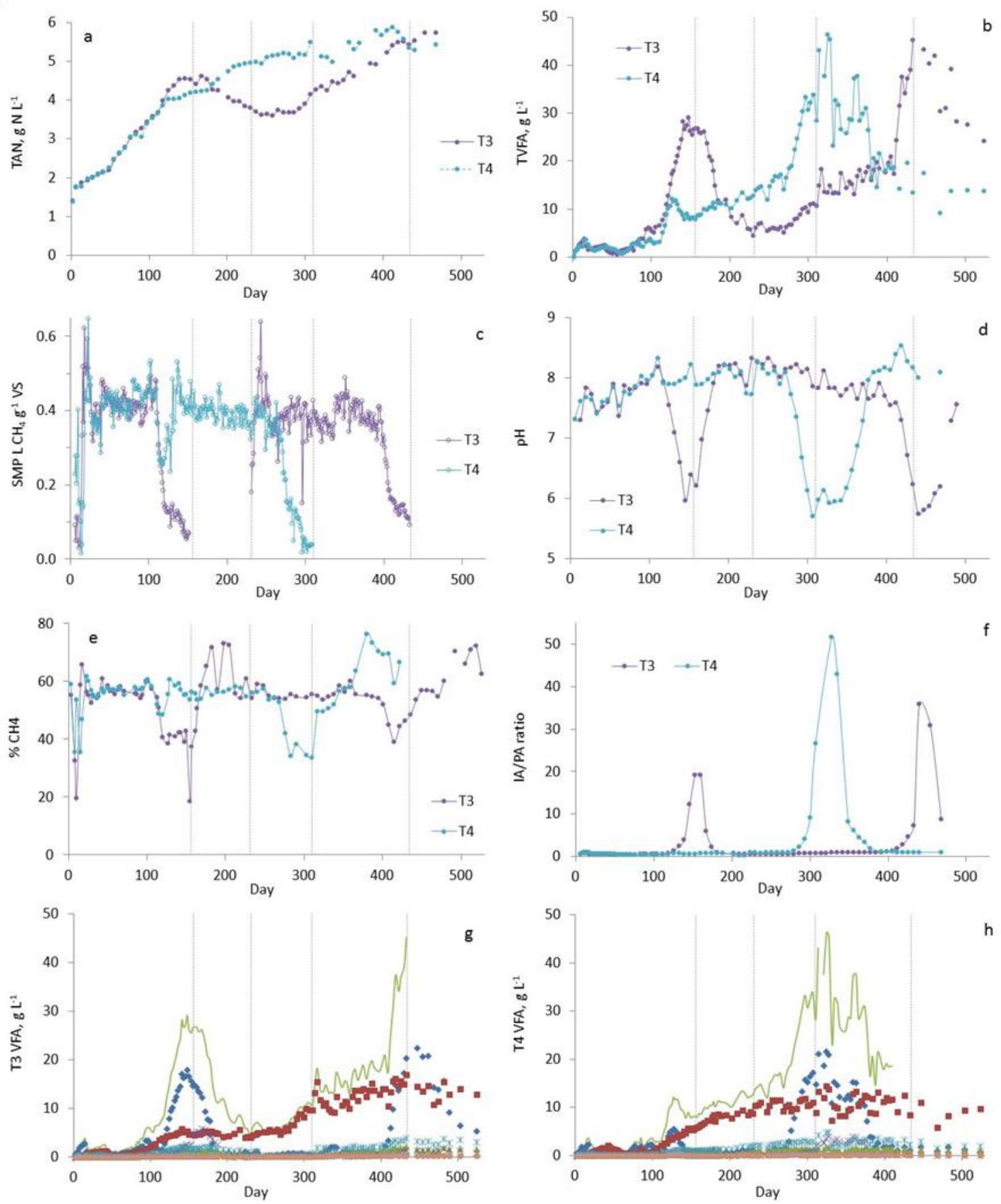

- Acetic . Propionic \& Iso-Butyric $\times$ n-Butyric

x Iso-Valeric

- Valeric + Hexanoic - Heptanoic - TVFA

Figure 4 Selected monitoring parameters during thermophilic digestion of high-N FW between days 0-530. (a) TAN, (b) TVFA (c) SMP, (d) pH, (e) biogas $\mathrm{CH}_{4}$ content, (f) IA/PA ratio, and VFA profiles in (g) T3 and (h) T4. Vertical dotted lines indicate a change in feeding in response to digester conditions. 

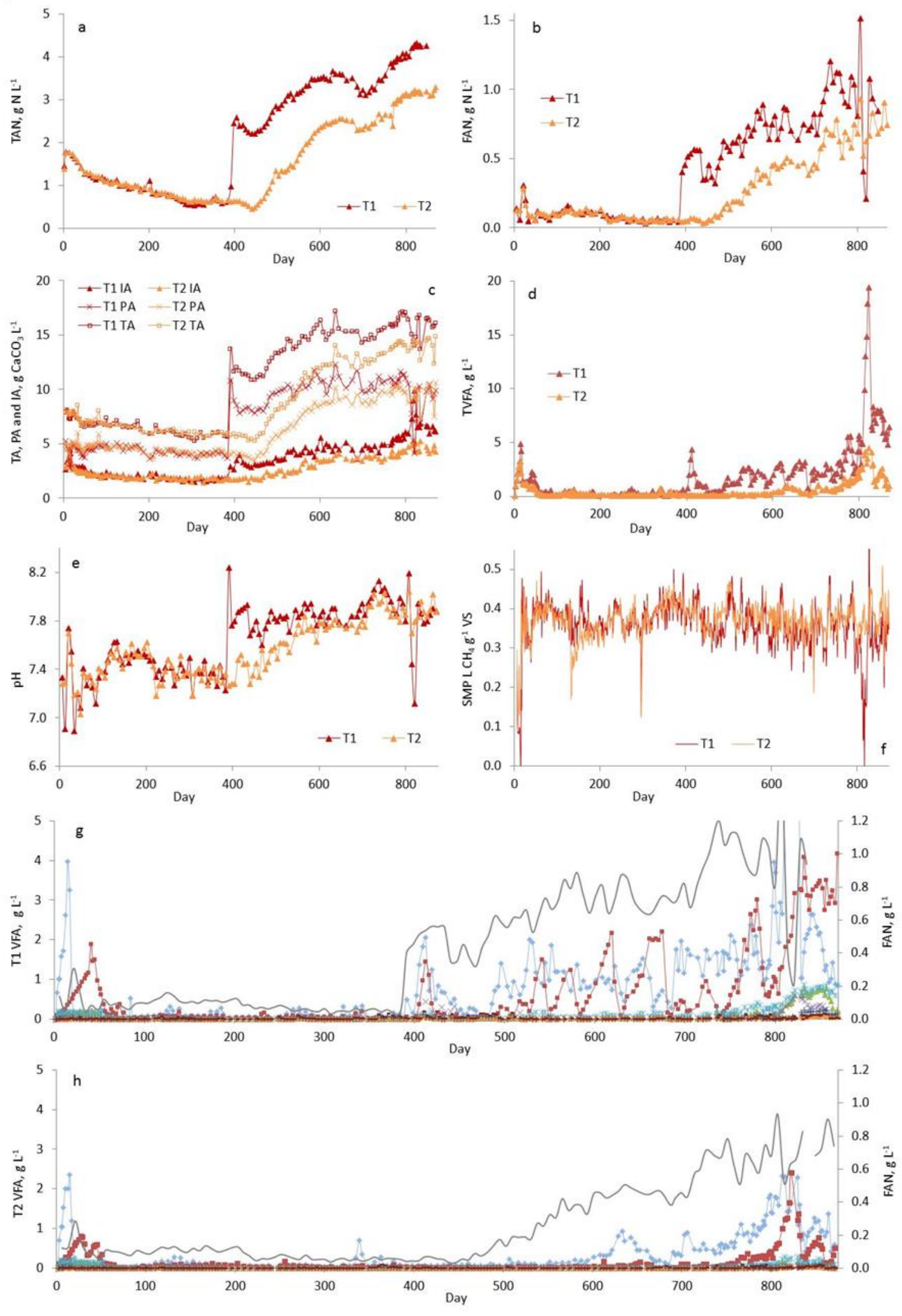

Figure 5 Selected monitoring parameters during thermophilic digestion of low-N FW. (a) TAN, (b) FAN, (c) alkalinity, (d) TVFA, e) pH, (f) SMP and VFA profiles and FAN in (g) $\mathrm{T} 1$ and (h) T2 during whole experiment including period with urea addition. 